Original Research Paper

\title{
Food Security Forecast within the Framework of Mankind Survival Strategy Concept in the Twenty-First Century
}

\author{
${ }^{1}$ Orazaly Sabden and ${ }^{2}$ Abdumalik Ashirov \\ ${ }^{1}$ The Institute of Economy of Committee of Science of the Ministry of Education and Science of the Republic of Kazakhstan, \\ Department of Industrialization, Competitiveness and Business, Almaty, Kazakhstan \\ ${ }^{2}$ South Kazakhstan State Pedagogical Institute, Department of Natural Science, Shymkent, Kazakhstan
}

Article history

Received: 03-12-2015

Revised: 09-01-2016

Accepted: 27-01-2016

Corresponding Author:

Abdumalik Ashirov

South Kazakhstan State

Pedagogical Institute,

Department of Natural Science,

Shymkent, Kazakhstan

Email: osabden@mail.ru

\begin{abstract}
The present article justifies the necessity of improving the food security planning within the framework of implementing the millennium development goals. In this regard, the study develops a brand new approach in the theory of methodology for assessing and monitoring the global food security, aimed at forecasting quantitative scenarios of its development. A distinctive advantage of this approach is the ability to forecast optimistic, pessimistic and realistic scenarios for provision of food security levels regarding certain groups of countries depending on their economic development. This approach utilizes subjectivity in the process of monitoring the provision of food security levels and contributes to optimizing the ways to increasing it in conditions of uncertainty.
\end{abstract}

Keywords: Mankind Survival Strategy for the 21st Century, Millennium Development Goals, Planning of Food Security Levels, Global Index, Food Security

\section{Introduction}

In the current context global problems of mankind survival came into focus of research in all areas of science in the twenty-first century (Shagaida and Uzun, 2015). Providing the population with a physiologically required minimum of food has become the fundamental basis of the concept. This is because mankind has so far failed to achieve the state, which is characterized by all human beings on the planet having constant access to food.

Food security is a multifold problem, both of international and national character, affecting every social group and every individual. This concept is embodied in the eight Millennium development goals and has remained a universal basis for the worldwide development over the past 15 years. Worldwide mobilization of efforts for implementing the Millennium development goals has been crowned with the most successful promotion of struggle against poverty in the history of mankind.

One of the key objectives of the mankind survival strategy is a liquidation of extreme poverty and hunger, realization of which had progressed dynamically in the 21 st century. The proportion of undernourished population in the world in 1996-2014 decreased by 5.3\% and accounted for $10.8 \%$ of the global population. Moreover, the food shortage is characterized by a considerably steady pace of its decline and there is a dynamic of reduction in its depth of $37 \mathrm{kcal}$ per person in the underdeveloped countries of the world in 19962014 (FAO, 2015).

A positive aspect in the process of implementing the mankind survival strategy is also a decrease in extreme poverty levels of 1090 million people in the developing countries and at the beginning of 2015 it reached $14 \%$ of population (FAO, 2015). Furthermore, the tendency of poverty reduction is characterized by sustained downward trend.

Meanwhile, the implementation of strategic Millennium development goals failed to ensure complete food security and targeted hunger reduction had not been achieved by 2015 . For example, the level of food security has slightly increased in the developing regions of the world especially in Oceania. The level of undernourishment decreased by only $1.7 \%$ in 2012-2014 compared to 1990-1992 (UN, 2015).

This trend is determined by the overstated plan indicators of target security achievement of 
economically underdeveloped region, the duration of the forecast period of the target indicators and the impossibility of their adjustment as well as by lack of consideration of variant food security levels, which has caused the ineffectiveness of measures to achieve it (Frayne and McCordic, 2015). In addition, there is a threat of a significantly higher rate of population growth as opposed to food provision in the countries of the world, especially in the economically underdeveloped regions. These factors precondition the development of effective methods for recording food security levels, approaches to forecasting it for the purpose of optimizing control and regulating of hunger in the world.

Therefore, this study is aimed at developing the forecast of scenarios of ensuring food security in order to minimize the uncertain conditions of implementing the targeted measures.

The global contradiction between the absolute surplus of food production in industrialized countries alongside with a mass hunger and undernourishment among the population of the third world countries caused the implementation of food security category by the UN Food and Agriculture Organization (FAO, 2015). This concept was associated with the achievement of three specific goals of the mankind survival strategy: Sufficiency of food supply, stability of its supply chain and markets as well as the provision of access to its supply (McKune et al., 2015).

Most modern scholars consider the indicative problems within the paradigm of food security provision (Aras and Kocakoç, 2015), focusing on the expansion of the system of indicators and the criteria for its evaluation (Rudel and Meyfroidt, 2014; Van Wijk, 2014).

The studies of food security characteristics in the countries with different levels of economic development are considered to be relevant (Revenko, 2015). Particularly, the issues related to overcoming hunger in the underdeveloped regions of the world were subjected to fundamental scientific elaboration (Seaman et al., 2014; Enenkel et al., 2015; Sharma and Prabhakar, 2014).

The problems of analytical evaluation and identification of trends in food security development were actively researched within the framework of the global mankind survival strategy in the twenty-first century (Sukharev, 2015; Fuss et al., 2015). The studies reviewed the problems of increasing the efficiency of planning and forecasting of food security levels and the ways of its provision (Slimane et al., 2015; Moseley, 2015). Moreover, most of the studies present the results of long-term forecasting of food security level for 15-30 years (Van Dijk and Meijerink, 2014; Sreejith and Selvan, 2015; Van Wijk, 2014).
However, as can be seen by the analysis of contemporary literature, the theory of evaluation mechanism of food security is lacking in studies concerning its medium-term planning or determining the forecasting scenarios of food security level for the purpose of optimizing its provision directions.

In this regard, the present study aims to eliminate the identified shortcomings as a qualitatively new dimension in the methodology of monitoring food security within the framework of global concept of mankind survival strategy in the 21 st century.

\section{Methods and Techniques}

The statistical data for 1997-2014 served as an analytical framework of the present study. About 12 food security indicators: Average dietary energy supply adequacy, Average value of food production, Average protein supply, Average supply of protein of animal origin, Gross domestic product per capita (in purchasing power equivalent), Domestic food price level index, Political stability and absence of violence/terrorism Domestic food price1 volatility index, Per capita food production variability, Per capita food supply variability, Percentage of population with access to improved water sources, Percentage of population with access to sanitation facilities (FAO, 2015).

The given choice of indicators is explained by the availability of their quantitative assessment for the specified period based on sample selection of 145 studied countries worldwide according to the data provided by (FAO, 2015).

The global food security indicators and the index of global food security as an integrated value of its components are the object of forecasting within the framework of the study (EG, 2015).

The period of perceptive scenario forecasting is defined within the interval of 6 years between 2015-2020.

As a forecasting approach, the author uses scenario method, which is a factographic one and is based on extrapolating the development trends into the future. The advantage of using the scenario method of forecasting food security level worldwide is expressed in the ability to clearly formulate and compare different probable or desirable development prospects.

The technical tools of developing scenarios forecast of food security level in the study is an artificial neural network, i.e., a mathematical model that represents a system of simple processors (artificial neurons) and connections between them determined by weighting indexes.

The neural network consists of structural and functional units of the simulated system. It converts the input signal into output using transferring and activation functions. Such units are called neurons. 
The current state of a neuron is determined by post synaptic potential function, which is calculated as a weighted sum of inputs including threshold value. For a neural network of multilayer perceptron type postsynaptic function has a linear mode:

$n e t_{j}=w_{0}+\sum_{i=1}^{N} x_{i} w_{i j}$

Where:

$n e t_{j}=$ Post-synaptic function

$w_{0}=$ Threshold value of function

$X_{I}=$ Input signal of $i$ neuron

$w_{i j}=$ Weight of synaptic connection between $i$-m and $j$ th neuron

$I, j=1.2, \ldots, N($ Borovikov, 2008)

The resulting value of the PSP-function is converted into the output signal by using the activation function:

$y_{j}=f\left(n e t_{j}\right)$

Where:

$y_{i} \quad=$ Output signal

$f\left(\right.$ net $\left._{j}\right)=$ Activation function (Borovikov, 2008)

In neural networks, depending on the nature of the interaction between neurons the following functions are used: A linear, logistic, hyperbolic, exponential, sinusoidal and piecewise-linear or step functions.

Neural network methods were used in regression and time series analysis to meet the challenges of forecasting scenarios of ensuring food security in the countries worldwide according to the technology of neural network modeling.

The regression analysis was used in the process of neural network modeling with the purpose of forecasting the components of the global food security index.

Neural network regression is a method of teaching the model, which explores the influence of one or more independent variables on the resulting one. The method of regression analysis is used in this study to obtain development scenarios of the dependent variable in the future, taking into account the influence of independent factors (Borovikov, 2008).

\section{Results}

Paradigm of mankind survival strategy in the $21 \mathrm{st}$ century has become the ground for refuting of Malthus theory of decreasing fertility and underdevelopment of agricultural sector of economy as fundamental factors of chronic food instability (Misra, 2014). This led to the beginning of a new food concept i.e., the provision of economic development and overcoming of poverty as key factors of food availability (Dimitri et al., 2015).

According to this statement in order to obtain the most appropriate forecast results within the framework of the study, the scenarios of food security level evolved differently in groups of countries according to their level of economic development based on classification of (FAO, 2015). This approach is considered to be correct and can be used to describe the options for future food security, taking into account the economic potential of the world regions and their needs.

The study grouped 12 indicators of global food security index according to country categories: Developed countries, developing countries and least developed countries.

Each indicator for each group of countries underwent forecasting by way of neural modeling based on the analysis of time periods in 2015-2020. Statistic data for 1997-2014 served as a basis for the forecast. At the same time, the process of modeling determined three forecast scenarios and their quantitative values: Pessimistic, realistic and optimistic. The forecasting scenarios were calculated based on the dynamic trends of core indicator forecasting values. The optimistic scenario considered the highest pace of indicators change. The optimistic scenario reflected the lowest kinetic pace of indicators. The realistic scenario was formed on the basis of average, the most probable changes of food security indicators.

Characteristics of adequacy of the neural model, as a result of the correctness and accuracy of forecast of food security components are presented in Table 1.

Since the values for the controlling, training and testing errors do not exceed 5\%, which indicates with $95 \%$ of probability, the adequacy of results of forecasting the scenarios of food security level indicators.

Using forecast indicators of scenarios for food security level, neural networks based on regression analysis have been built for calculation of global food security index by groups of countries in accordance with their level of economic development (Fig. 1-3).

Adequacy of neural models of forecasting scenarios is confirmed by parametric characteristics (Table 2).

Forecasting scenarios of global food security index level by groups of countries worldwide in 2015-2020, presented in Table 3. 


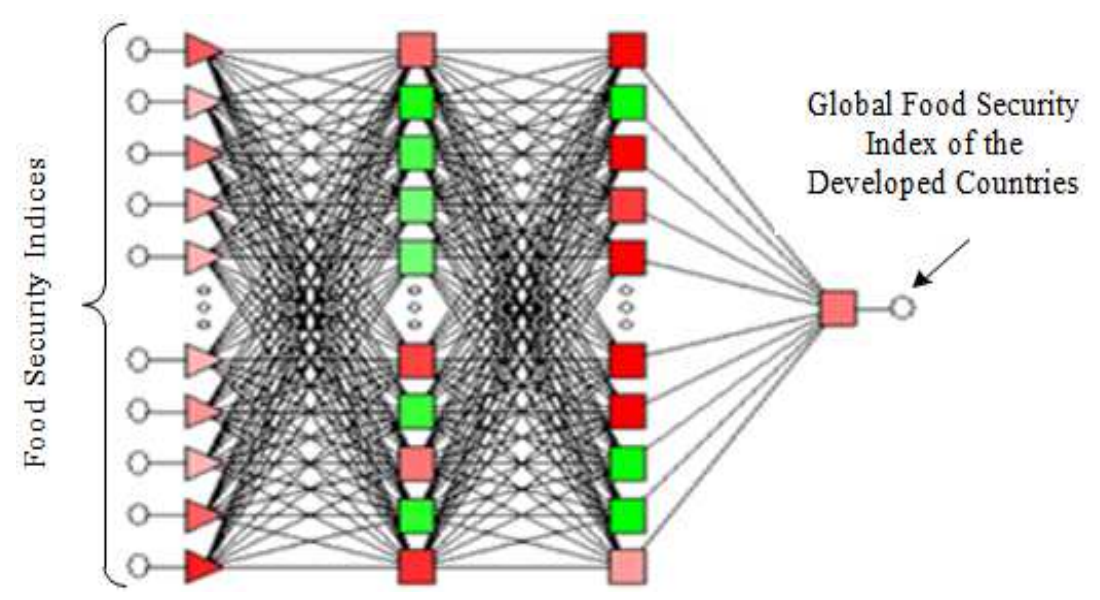

Fig. 1. Neural network of forecasting scenarios ensuring the level of global food security index in the developed countries

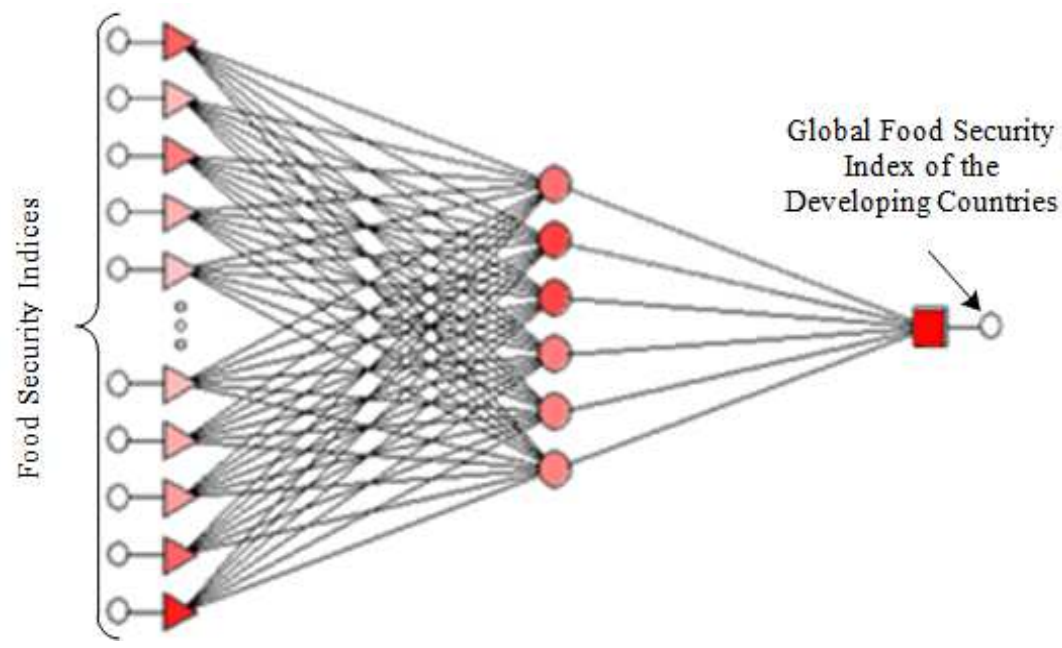

Fig. 2. Neural network of forecasting scenarios ensuring global food security index level of the developing countries

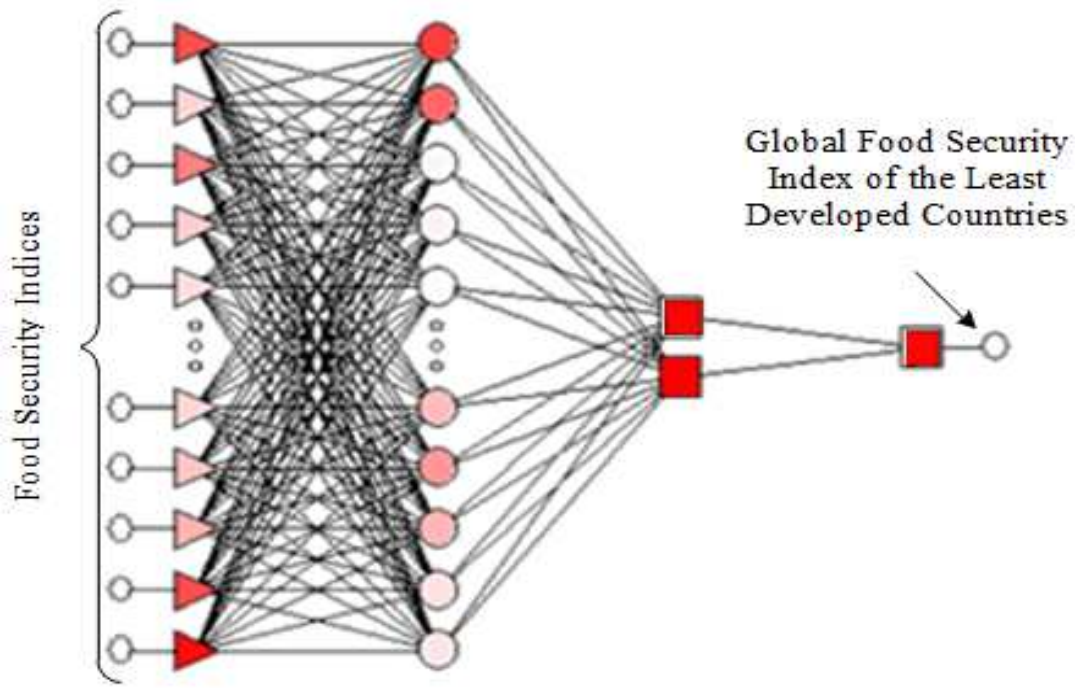

Fig. 3. Neural network of forecasting the provision of the global food security index level in the least developed countries 
Table 1. Characteristics of the adequacy of forecast models of food security levels indicators according to the scenarios of their development

\begin{tabular}{|c|c|c|c|c|c|}
\hline Indicator & Scenario & Network architecture & Training error & Control error & Testing error \\
\hline \multirow{3}{*}{ Average dietary energy supply adequacy } & Pessimistic & MP s5 1: 5-3-1: 1 & 0.0125 & 0.0347 & 0.0107 \\
\hline & Realistic & MP s5 1: 5-18-5-1: 1 & 0.0229 & 0.0253 & 0.0265 \\
\hline & Optimistic & ORNS s5 1: 5-4-2-1: 1 & 0.0281 & 0.0352 & 0.0166 \\
\hline \multirow{3}{*}{ Average value of food production } & Pessimistic & RBF s5 1: 5-1-1: 1 & 0.0074 & 0.0285 & 0.0217 \\
\hline & Realistic & ORNS s5 1: 5-4-2-1: 1 & 0.0206 & 0.0358 & 0.0376 \\
\hline & Optimistic & MP s5 1: 5-8-1: 1 & 0.0073 & 0.0163 & 0.0288 \\
\hline \multirow[t]{3}{*}{ Average protein supply } & Pessimistic & RBF s5 1: 5-1-1: 1 & 0.0183 & 0.0358 & 0.0103 \\
\hline & Realistic & OPHC s3 1:3-4-2-1:1 & 0.0300 & 0.0353 & 0.0153 \\
\hline & Optimistic & MP s5 1: 5-2-1: 1 & 0.0293 & 0.0135 & 0.0459 \\
\hline \multirow{3}{*}{$\begin{array}{l}\text { Average supply of } \\
\text { protein of animal origin }\end{array}$} & Pessimistic & ORNS s5 1: 5-8-2-1: 1 & 0.0189 & 0.0170 & 0.0383 \\
\hline & Realistic & RBF s5 1: 5-2-1: 1 & 0.0165 & 0.0157 & 0.0260 \\
\hline & Optimistic & RBF s5 1: 5-4-1: 1 & 0.0176 & 0.0133 & 0.0171 \\
\hline \multirow{3}{*}{$\begin{array}{l}\text { Gross domestic product per capita } \\
\text { (in purchasing power equivalent) }\end{array}$} & Pessimistic & RBF s5 1: 5-2-1: 1 & 0.0281 & 0.0299 & 0.0375 \\
\hline & Realistic & ORNS s5 1: 5-8-2-1: 1 & 0.0257 & 0.0416 & 0.0459 \\
\hline & Optimistic & MP s5 1: 5-4-1: 1 & 0.0387 & 0.0378 & 0.0272 \\
\hline \multirow{3}{*}{ Domestic food price level index } & Pessimistic & ORNS s3 1: $3-8-2-1: 1$ & 0.0166 & 0.0031 & 0.0344 \\
\hline & Realistic & ORNS s5 1: 5-8-2-1: 1 & 0.0318 & 0.0245 & 0.0141 \\
\hline & Optimistic & MP s5 1: 5-8-1: 1 & 0.0266 & 0.0031 & 0.0344 \\
\hline \multirow{3}{*}{$\begin{array}{l}\text { Political stability and absence of } \\
\text { violence/terrorism }\end{array}$} & Pessimistic & MP s5 1: 5-9-1: 1 & 0.0408 & 0.0430 & 0.0315 \\
\hline & Realistic & MP s5 1: 5-8-4-1: 1 & 0.0297 & 0.0458 & 0.0322 \\
\hline & Optimistic & RBF s5 1: 5-1-1: 1 & 0.0365 & 0.0274 & 0.0250 \\
\hline \multirow[t]{3}{*}{ Domestic food price volatility index } & Pessimistic & MP s5 1: 5-2-1: 1 & 0.0367 & 0.0353 & 0.0250 \\
\hline & Realistic & RBF s5 1: 5-1-1: 1 & 0.0253 & 0.0188 & 0.0298 \\
\hline & Optimistic & MP s5 1: 5-8-8-1: 1 & 0.0195 & 0.0262 & 0.0234 \\
\hline \multirow[t]{3}{*}{ Per capita food production variability } & Pessimistic & RBF s5 1: 5-2-1: 1 & 0.0192 & 0.0186 & 0.0415 \\
\hline & Realistic & OPHC s5 1:5-6-2-1:1 & 0.0207 & 0.0197 & 0.0260 \\
\hline & Optimistic & MP s5 1: 5-8-1: 1 & 0.0285 & 0.0160 & 0.0186 \\
\hline \multirow[t]{3}{*}{ Per capita food supply variability } & Pessimistic & RBF s5 1: 5-3-1: 1 & 0.0202 & 0.0179 & 0.0195 \\
\hline & Realistic & MP s5 1: 5-8-1: 1 & 0.0395 & 0.0194 & 0.0112 \\
\hline & Optimistic & MP s5 1: 5-8-7-1: 1 & 0.0278 & 0.0232 & 0.0324 \\
\hline \multirow{3}{*}{$\begin{array}{l}\text { Percentage of population with access } \\
\text { to improved water sources }\end{array}$} & Pessimistic & RBF s5 1: 5-2-1: 1 & 0.0480 & 0.0377 & 0.0361 \\
\hline & Realistic & ORNC s3 1:3-6-2-1:1 & 0.0345 & 0.0385 & 0.0036 \\
\hline & Optimistic & MP s5 1: 5-8-1: 1 & 0.0174 & 0.0357 & 0.0122 \\
\hline \multirow{3}{*}{$\begin{array}{l}\text { Percentage of population } \\
\text { with access to sanitation facilities }\end{array}$} & Pessimistic & ORNC s3 1:3-6-2-1:1 & 0.0267 & 0.0483 & 0.0140 \\
\hline & Realistic & RBF s5 1: 5-2-1: 1 & 0.0169 & 0.0154 & 0.0356 \\
\hline & Optimistic & MP s5 $1: 5-5-1: 1$ & 0.0102 & 0.0150 & 0.0336 \\
\hline
\end{tabular}

Table 2. Characteristics of neural models forecasting scenarios of providing the global food security index level by groups of countries

\begin{tabular}{lllll}
\hline Groups of countries & Network architecture & Training error & Control error & Testing error \\
\hline Developed countries & MP 12:12 -27 -13-1:1 & 0.0079 & 0.0241 & 0.0250 \\
Developing countries & RBF 12:12-6 -1:1 & 0.0144 & 0.0022 & 0.0181 \\
Least developed countries & ORNC 12:12 -57-2 -1:1 & 0.0085 & 0.0076 & 0.0285 \\
\hline
\end{tabular}

Table 3. Forecasting scenario of ensuring food security index level of countries worldwide according to their level of economic development in 2015-2020

\begin{tabular}{|c|c|c|c|c|c|c|c|c|c|}
\hline \multirow{2}{*}{$\begin{array}{l}\text { Forecasting } \\
\text { period }\end{array}$} & \multicolumn{3}{|c|}{ Developing countries } & \multicolumn{3}{|c|}{ Developed countries } & \multicolumn{3}{|c|}{ Least developed countries } \\
\hline & Pessimistic & Realistic & Optimistic & Pessimistic & Realistic & Optimistic & $\underline{\text { Pessimistic }}$ & Realistic & Optimistic \\
\hline 2015 & 107.42 & 107.95 & 108.40 & 115.46 & 115.91 & 116.07 & 70.85 & 76.47 & 81.97 \\
\hline 2016 & 107.54 & 108.41 & 109.31 & 115.59 & 115.96 & 116.30 & 70.97 & 76.75 & 82.72 \\
\hline 2017 & 107.75 & 109.06 & 110.21 & 115.88 & 116.19 & 116.64 & 71.14 & 77.29 & 83.81 \\
\hline 2018 & 107.85 & 109.66 & 110.99 & 116.01 & 116.44 & 116.88 & 71.65 & 77.91 & 84.52 \\
\hline 2019 & 108.46 & 110.15 & 111.80 & 116.03 & 116.60 & 117.33 & 71.87 & 77.25 & 85.32 \\
\hline 2020 & 108.94 & 110.56 & 112.28 & 116.10 & 116.74 & 117.43 & 72.17 & 78.69 & 85.93 \\
\hline
\end{tabular}

\section{Discussion}

The study formulated three forecasting scenarios of providing the global food security index level. For the most economically developed countries (according to three scenarios) food security index is characterized by the highest indicators on sample selection. This index reflects the positive dynamics of its development. Moreover, it should also be noted that there was an insignificant gap in food security index values according to the development scenarios. The average value of deviation of the pessimistic scenario of ensuring food security from realistic one is only $0.6 \%$ for the period 6 years. The average deviation of forecasting values for the optimistic scenario is also insignificant-only $0.4 \%$ (Table 4 ). 
Table 4. The deviation of indicators of forecast scenarios regarding food security index level relating to the realistic scenario for groups of countries, \%

\begin{tabular}{|c|c|c|c|c|c|c|}
\hline \multirow[b]{2}{*}{$\begin{array}{l}\text { Forecasting } \\
\text { period }\end{array}$} & \multicolumn{2}{|c|}{ Developing countries } & \multicolumn{2}{|c|}{ Developed countries } & \multicolumn{2}{|c|}{ Least developed countries } \\
\hline & $\begin{array}{l}\text { Pessimistic } \\
\text { /realistic }\end{array}$ & $\begin{array}{l}\text { Optimistic } \\
\text { /realistic }\end{array}$ & $\begin{array}{l}\text { Pessimistic } \\
\text { /realistic }\end{array}$ & $\begin{array}{l}\text { Optimistic } \\
\text { /realistic }\end{array}$ & $\begin{array}{l}\text { Pessimistic } \\
\text { /realistic }\end{array}$ & $\begin{array}{l}\text { Optimistic } \\
\text { /realistic }\end{array}$ \\
\hline 2015 & 99.51 & 100.42 & 99.61 & 100.14 & 92.65 & 107.20 \\
\hline 2016 & 99.20 & 100.83 & 99.69 & 100.30 & 92.47 & 107.79 \\
\hline 2017 & 98.79 & 101.05 & 99.74 & 100.39 & 92.04 & 108.43 \\
\hline 2018 & 98.35 & 101.21 & 99.63 & 100.38 & 91.97 & 108.49 \\
\hline 2019 & 98.46 & 101.50 & 99.51 & 100.62 & 93.03 & 110.44 \\
\hline 2020 & 98.53 & 101.56 & 99.45 & 100.59 & 91.71 & 109.19 \\
\hline Average & 98.81 & 101.10 & 99.60 & 100.40 & 92.65 & 107.20 \\
\hline
\end{tabular}

Developing countries are also characterized by quite high level of food security. The relative deviation of the average forecast index value in the realistic scenario in the developing countries is less than $6.4 \%$ compared to the level of the developed countries. But it should be noted that there is a higher performance index variation between the development scenarios. This is due to the fact that the growth rate of food security is $0.33 \%$ higher than in the developed economies. This gives ground for making an assumption about nearest prospect of food security level in the developing countries reaching the level of the developed countries.

Based on the results of the study, it can be confirmed that the level of food security in countries with the developed and developing economies is at considerably high level of provision and in the medium-term prospect, its sustainability is expected to grow steadily without major fluctuations. This indicates the effectiveness of government measures to ensure it.

Practically, the most valuable are the results of the forecast for the least developed countries in the world. Thus, they are characterized by a positive trend in the development of all the forecast scenarios. However, a low food security index level in comparison with other groups of countries of the world, even according to the optimistic scenario should be pointed out. The average level of food security in the realistic scenario for the 6 years ahead may reach the level of 77.39 only and optimistically 84.04. The high level of indicator deviation of forecast scenarios. Deviation of food security level in implementing the pessimistic scenario accounts of $8 \%$ compared to the realistic one and the ratio between the optimistic to realistic scenario is $7.2 \%$.

\section{Conclusion and Further Research}

The results of an empirical study allowed us to make the following conclusions:

- Non-fulfillment of strategic tasks for provision of food security within the framework of implementation of the Millennium development goals preconditions the need to improve approaches to planning and forecasting of its level depending on the potential economic opportunities of the countries worldwide

- In the course of the study we formed pessimistic, realistic and optimistic forecast scenarios by using neural forecasting tools of food security provision based on groups of countries according to their level of economic development in 2015-2020

- On the basis of forecasting scenarios it was concluded that in the medium-term prospect food security in the developed and developing countries has a positive trend and is characterized by the stability of its development

- It was found that the increase of food security level in the least developed countries considerably depends on the intensity of ongoing activities aimed at its provision. This is evidenced by a significant differentiability of index level values of food security between the development scenarios

- The elaboration of forecast scenarios for the development of food security as a conceptual approach in the paradigm of monitoring of food availability makes it possible to form of variant areas of food availability in face of uncertainty. It allows us to determine the consequences in the event of alternative solutions to make timely strategy adjustment in order to optimize the results, which is especially actualized in terms of improving food security problems in the underdeveloped countries

- The presented approach to the definition of strategic guidelines and target food security is the basis for improving the methodology of evaluation and planning of food availability in terms of the strategy of ensuring the survival of humanity in the 21 st century

- The results of the study formed the conceptual basis for further scientific research in this field, in particular-the identification of factors and trends for achieving the optimistic scenario of food security in the world 


\section{Acknowledgement}

The research was performed at the Institute of Economics of the Committee of Science, Ministry of Education and Science of the Republic of Kazakhstan (RK MES), as well as in the A. Yassawi International Kazakh-Turkish University, RK MOS and in the laboratory of Chimkent Pedagogical Institute. The authors would like to thank all the staff who assisted in the investigation.

\section{Author's Contributions}

The authors have contributed equally to the research and writing of the manuscript.

\section{Ethics}

The authors have no conflicts of interest in the development of the research and publication of this article.

\section{References}

Aras, S. and I.D. Kocakoç, 2015. A new model selection strategy in time series forecasting with artificial neural networks: IHTS. Neurocomputing, 174: 974-987. DOI: 10.1016/j.neucom.2015.10.036

Borovikov, V., 2008. Neural Networks, STATISTIC Neural Networks: Methodology and technology of modern data analysis. Hotline-Telecom, Moscow, ISBN: 978-5-9912-0015-8, pp: 392.

Dimitri, C., L. Oberholtzer, M. Zive and C. Sandolo, 2015. Enhancing food security of low-income consumers: An investigation of financial incentives for use at farmers markets. Food Policy, 52: 64-70. DOI: 10.1016/j.foodpol.2014.06.002

Enenkel, M., L. See, R. Bonifacio, V. Boken and N. Chaney et al., 2015. Drought and food security is improving decision-support via new technologies and innovative collaboration. Global Food Security, 4: 51-55. DOI: 10.1016/j.gfs.2014.08.005

FAO, 2015. Food and agriculture organization of the United Nations.

Frayne, B. and C. McCordic, 2015. Planning for food secure cities: Measuring the influence of infrastructure and income on household food security in Southern African cities. Geoforum, 65: 1-11. DOI: 10.1016/j.geoforum.2015.06.025

Fuss, S., P. Havlík, J. Szolgayová, E. Schmid and W.H. Reuter et al., 2015. Global food security under crop adaptation and yield volatility. Technological Forecasting Social Change, 98: 223-233. DOI: $10.1016 /$ j.techfore.2015.03.019

McKune, S.L., E.C. Borresen, A.G. Young, T.D. Auria Ryley and S.L. Russo et al., 2015. Climate change through a gendered lens: Examining livestock holder food security. Global Food Security, 6: 1-8.

DOI: $10.1016 /$ j.gfs.2015.05.001
Misra, A., 2014. Climate change and challenges of water and food security. Int. J. Sustainable Built Environ., 3: 153-165. DOI: 10.1016/j.ijsbe.2014.04.006

Moseley, W.G., 2015. Food Security and 'Green Revolution'. In: International Encyclopedia of the Social and Behavioral Sciences, Wright, J.D. (Ed.), Elsevier Science, Amsterdam, ISBN-10: 0080970877, pp: 307-310.

Revenko, L., 2015. Parameters and food safety risks. Int. Process., 13: 6-20.

Rudel, T. and P. Meyfroidt, 2014. Self-organizing anarchy: The food security-biodiversity-climate crisis and the genesis of rural land use planning in the developing world. Land Use Policy, 36: 239-247. DOI: 10.1016/j.landusepol.2013.07.008

Seaman, J., G. Sawdon, J. Acidriand and C. Petty, 2014. The household economy approach. Managing the impact of climate change on poverty and food security in developing countries. Climate Risk Manage., 4: 59-68. DOI: 10.1016/j.crm.2014.10.001

Shagaida, N. and B. Uzun, 2015. Food Security: Problems of evaluation. Economics Issues, 5: 63-78.

Sharma, H. and C. Prabhakar, 2014. Chapter 2-Impact of climate change on pest management and food security. Integrated Pest Manage., 23-36. DOI: 10.1016/B978-0-12-398529-3.00003-8

Slimane, M., M. Huchet-Bourdon and H. Zitouna, 2015. The role of sectoral FDI in promoting agricultural production and improving food security. Int. Econom. DOI: 10.1016/j.inteco.2015.06.001

Sreejith, S. and S.P. Selvan, 2015. Analysis of FACTS devices on security constrained unit commitment problem. Int. J. Electrical Power Energy Syst., 66: 280-293. DOI: 10.1016/j.ijepes.2014.10.049

Sukharev, O.S., 2015. Institutional challenges to food security of Russia. J. National Interests: Priorities Security, 6: 44-53.

EG, 2015. Global food security index. The Economist Group.

UN, 2015. The millennium development goals report 2015. United Nations, New York, ISBN-10: 978-92-1-101320-7, pp: 75.

Van Dijk, M. and G.W. Meijerink, 2014. A review of global food security scenario and assessment studies: Results, gaps and research priorities. Global Food Security, 3: 227-238. DOI: 10.1016/j.gfs.2014.09.004

Van Wijk, M.T., 2014. From global economic modelling to household level analyses of food security and sustainability: How big is the gap and can we bridge it? Food Policy, 49: 378-388. DOI: $10.1016 /$ j.foodpol.2014.10.003 